\section{$\underset{\text { hommes }}{\text { \& migrations }}$}

\section{Hommes \& migrations}

Revue française de référence sur les dynamiques

migratoires

$1310 \mid 2015$

Fashion Mix

\title{
Barsegh Chahbaz, Le Pays d'Ararat le sait
}

éd. CPA-Valence Romans Sud Rhône-Alpes, 2015, 72 p., 12 euros

\section{Laure Piaton}

\section{OpenEdition}

1 Journals

\section{Édition électronique}

URL : http://journals.openedition.org/hommesmigrations/3215

DOI : 10.4000/hommesmigrations.3215

ISSN : 2262-3353

\section{Éditeur}

Musée national de l'histoire de l'immigration

\section{Édition imprimée}

Date de publication : 1 avril 2015

Pagination : 197-198

ISBN : 978-2-919040-31-5

ISSN : $1142-852 X$

\section{Référence électronique}

Laure Piaton, «Barsegh Chahbaz, Le Pays d'Ararat le sait », Hommes \& migrations [En ligne], $1310 \mid 2015$, mis en ligne le 17 décembre 2015, consulté le 24 septembre 2020. URL : http://

journals.openedition.org/hommesmigrations/3215; DOI : https://doi.org/10.4000/

hommesmigrations.3215 
par amour du silence, mais par incapacité de communiquer". L'héritage colle aux basques! À Paris aussi, il ne disait pas tout à ses amis français. Par honte, il cachait son passé et son histoire. De cette honte, il allait avoir honte, "car il ressentit aussi combien il tenait à tout cela, à tout ce mauvais goût si familier, si cher à son cœur". Martin, à la différence de son père, et de sa doctoresse de sœur, insatisfaite et envieuse, a eu le

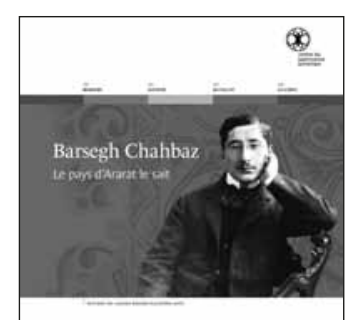

\section{Textes réunis, traduits et présentés par Léon Ketcheyan Barsegh Chahbaz, Le Pays d'Ararat le sait}

éd. CPA-Valence Romans Sud Rhône-Alpes, 2015, 72 p., 12 euros

Le Pays d'Ararat le sait réunit trois textes traduits de l'arménien, autour de la figure de Barsegh Chahbaz, intellectuel raflé à Istanbul le 24 avril 1915. Ce jour-là, à l'instar des représentants politiques, cadres et notables arméniens, Barsegh Charbaz est arrêté et déporté. Ce jour-là, débute la mise en œuvre du plan d'exécution concerté d'extermination des Arméniens.

Cet ouvrage s'appuie sur une importante donation reçue par le Centre du patrimoine arménien en 2013 en provenance du fonds Bassmadjian, dans laquelle se trouvait la dernière lettre qu'il adressa à sa sœur et à son épouse sur le chemin de sa déportation. Reproduite in extenso, cette archive est un courage de partir, le courage de refuser de se soumettre, "malgré ses penchants hérités pour la défaite". À Michalovce, il lui faudra recoller "les morceaux cassés et désintégrés de sa vie". Renouer avec l'enfance et les siens. Avec son père. Retisser les fils entremêlés, visibles et invisibles de son identité. Réunir les strates de son histoire, jusqu'aux plus lointaines. Celles oubliées au fin fond de cet Eastern européen. M. H.

témoignage rare et nous plonge au cœur du processus. Véritable supplique, elle dit toute sa détresse, la dureté des conditions de sa déportation, et sa méprise quand il croit possible encore de plaider sa cause et refuse de renoncer. De manière inédite, les propos introductifs de Léon Ketcheyan appréhendent les événements du 24 avril en observant le contexte géopolitique, les stratégies des chancelleries, le jeu des empires et les rivalités coloniales. Ils n'ignorent pas non plus les errements de la classe politique arménienne qui vont conduire les Arméniens au désastre : légitimiste à l'égard de son parti, Barsegh Chahbaz reste loyal à l'égard de l'Empire ottoman dont il est ressortissant. En rentrant à Constantinople dès le début de la guerre, il précipite sa perte.

Pour mieux cerner la personnalité de Barsegh Chahbaz et restituer la vie sociale, politique et militante des Arméniens à la veille de 1915 comme aux premières heures de leur déportation, Léon Ketcheyan présente également deux autres textes. Le premier, un long article publié aux États-Unis en 1965 
par Minas Katchatourian, nous permet de découvrir à travers Chahbaz, par de larges extraits de correspondance, l'étudiant engagé, le combattant politique et le défenseur des droits du peuple arménien. Il plonge le lecteur au cœur des débats qui agitent les élites arméniennes au début du XXe siècle, laisse deviner le désabusement qui le gagne, l'intellectuel qui l'emporte sur le militant. Ses écrits révèlent la grande lucidité politique de Barsegh Chahbaz, sa maturité et son caractère pragmatique. Le second se déroule à Aya, dans la prison devenue "le cimetière des intellectuels arméniens", où le destin fait se croiser Barsegh Chahbaz et Avétis
Nakashian, médecin, un des rares prisonniers ayant survécu.

Son récit, La prison d'Aya, publié à Alep en 1930, éclaire les conditions de leur détention, l'angoisse qui les étreint mais également l'incompréhension et l'indignation face au traitement qui leur est réservé.

À travers la figure de Barsegh Chahbaz, cet ouvrage laisse entrevoir le destin tragique de tant d'autres qui, comme lui, commençaient tout juste leur carrière en tant qu'écrivain ou poète, maître d'école ou médecin, personnalité engagée ou militant politique, les futures générations d'intellectuels arméniens tombés en 1915. Laure Piaton 